\title{
Monitoring North Atlantic right whale Eubalaena glacialis entanglement rates: a 30 yr retrospective
}

\author{
Amy R. Knowlton*, Philip K. Hamilton, Marilyn K. Marx, Heather M. Pettis, \\ Scott D. Kraus
}

New England Aquarium, John H. Prescott Marine Laboratory, Central Wharf, Boston, Massachusetts 02110, USA

\begin{abstract}
Entanglement in non-mobile fishing gear has been identified as one of the leading causes of mortality in North Atlantic right whales Eubalaena glacialis. To investigate this issue further, all available photographs of right whales taken from 1980 to 2009 were examined for evidence of entanglement with gear used in fisheries based on presence of rope or netting on the whale or scars inferred to have been caused by an encounter with rope. Photographs of 626 individual whales were assessed and 1032 unique entanglement events were documented. Of the 626 animals, $519(82.9 \%)$ had been entangled at least once and 306 of the $519(59.0 \%)$ had been entangled more than once. Males and females were entangled at similar rates. Juveniles were entangled at a higher rate than adults. On average, $25.9 \%$ of adequately photographed animals acquired new wounds or scars from fishing gear annually with no significant trend over time detected. However, the annual percentage of animals observed with rope on the body increased significantly during the study period, suggesting that it is becoming more difficult for whales to free themselves completely from fishing gear. Such high annual rates of entanglement remain a serious conservation concern for right whales because entanglements can have both lethal and sub-lethal effects. Federally required changes to fixed-gear fisheries in US waters have not reduced serious injuries and mortality to legally required levels. Here we show how documenting various annual rates of entanglement can monitor progress and impacts that fishing gear regulations may have on right whale recovery.
\end{abstract}

KEY WORDS: North Atlantic right whale - Eubalaena glacialis - Fishing gear - Entanglement · Scars $\cdot$ Conservation

\section{INTRODUCTION}

The North Atlantic right whale Eubalaena glacialis is an endangered species, numbering around 500 individuals (see 2011 Right Whale Report Card at www.narwc.org/pdf/2011_report_card_addendum. pdf). Entanglement in non-mobile fishing gear, including pot (trap) and gillnet gear, has been identified as one of the leading causes of mortality in this small, well-studied population (Kraus et al. 2005). Both living and dead right whales have been documented with rope through the mouth and/or wrapped around other body parts, including flippers and flukes (Knowlton \& Kraus 2001, Moore et al. 2004, Cassoff et al. 2011). Rope that has been retrieved from entangled right whales and humpbacks along the east coast of the USA and Canada has been found to come from non-mobile fisheries such as lobster and gillnet gear in $80 \%$ of the cases (Johnson et al. 2005). The remaining $20 \%$ of the cases carried rope that was not identifiable as to source.

In addition to those animals seen bearing rope, right whales have been documented with acute wounds, chronic unhealed wounds, and scars determined to be the result of contact with rope based on evidence of wrapping (Kraus 1990). The majority of 
these entanglement injuries are scars as opposed to acute or chronic wounds; thus, the term 'scar' is used throughout this paper to describe both scars and wounds. Since the source of rope retrieved from large whales has been linked to non-mobile fisheries in all cases where a source could be determined, it is assumed that any animal documented with a wrapping scar encountered rope that was fisheries related. The event is referred to as an 'entanglement' whether gear was present or not. Previous studies have assessed the level of entanglement in this population using a comprehensive, longitudinal photo-identification catalog of photographed sightings from multiple researchers, herein referred to as the 'Catalog', curated by the New England Aquarium for the North Atlantic Right Whale Consortium (http://rwcatalog.neaq.org/Terms.aspx, Hamilton et al. 2007). In the initial study, Kraus (1990) found that $57 \%$ of North Atlantic right whales with adequate photographs of the caudal peduncle (the area where entanglement scarring is most prevalent) had entanglement scars or were bearing rope from entanglement. Since then, photographic monitoring has revealed increasing levels of right whale entanglement: $61.5 \%$ in 1995 (Hamilton et al. 1998) and $72.6 \%$ in 2004 (Knowlton et al. 2008). Such entanglements have a wide range of impacts, from minimal scarring to chronic and sometimes fatal injury. Whatever the outcome, each event likely stresses the animal and may interrupt its normal activity for a short or long period (Hunt et al. 2006).

To address the entanglement problems facing this endangered species, the US NOAA's National Marine Fisheries Service (NMFS), under the mandate of the Marine Mammal Protection Act of 1972, convened the Atlantic Large Whale Take Reduction Team (www.nero.noaa.gov/whaletrp/) to develop a plan to reduce injuries and deaths of large whales due to incidental entanglement in fishing gear. The plan includes restrictions on where and how gear can be set; research into whale population biology and behavior, fishing gear interactions and the effects of fishing gear modifications; outreach to inform and collaborate with fishermen; and a large-whale disentanglement program. This team has been in place since 1996 and has helped NMFS formulate a variety of both regulatory and non-regulatory measures that have been implemented since the advent of the plan in 1997.

Determining where and how to mitigate entanglement interactions is challenging. Events in which whales come into contact with fishing gear are rarely observed directly (Weinrich 1999, Knowlton 2005); thus, most locations where entanglement interactions occur are not known. However, the limited cases where retrieved gear has been linked to a fisherman and/or locale indicate that entanglements occur all along the eastern seaboard in US and Canadian waters.

Although population-wide entanglement levels of right whales have been documented previously, understanding the annual rate and severity of encounters with fishing gear is important for determining whether management changes to non-mobile fishing gear are successful in reducing the frequency and severity of interactions. In this study both unique entanglement scarring events and the occurrence of animals seen bearing fishing gear were used to determine rates of entanglement as well as trends over time. These data were also used to evaluate the role of demography in entanglements, as well as the strengths and limitations of the data and analyses for monitoring.

\section{METHODS}

\section{Photographic identification and catalog curation}

Right whales have been photographed throughout their known range from Florida, USA, to Nova Scotia, Canada, and occasionally beyond, and are individually identifiable based on natural markings on their heads and by scars (Kraus et al. 1986). Each photographed sighting event is entered into a relational database with date, time, location, observer, and the recorded behavior and/or activity of the whale(s). All photographs and associated data collected by cooperating research organizations and individuals have been incorporated into the Catalog. As of February 2012, 626 cataloged animals observed between 1980 and 2009 were available to be used in this study. Although some photographs taken between 1935 and 1979 are included in the Catalog, they are insufficient to support meaningful analyses of entanglement rates, so data collected prior to 1980 were omitted from this analysis.

\section{Identifying entanglement events}

To identify entanglement events, all available photographs of an individual right whale were reviewed for the presence of (1) fishing gear on the whale (regardless of whether or not scars were present) or (2) scarring from past entanglements. 
Previous Catalog records of whales that survived entanglements, where whales were either cut free or freed themselves, have provided multiple records of scarring characteristics due to entangling fishing gear. For a scar to be attributed to entanglement, it had to show evidence of the rope having 'wrapped' on a given body part following Kraus (1990). Common points of contact are shown in Fig. 1, although wrapping scars can occur anywhere on the body. Scars for which any uncertainty existed about the source or cause were not included.

All sightings of an individual within a geographic area in a given year were combined into one record referred to as a 'batch.' Because not all body parts are photographed at each sighting, 'batching' allows for a larger suite of photographs to be used to determine the absence or presence of scars and gear. If an animal was not sighted for more than a month, a new batch was created even if the whale was seen in the same habitat later in the year. For coding purposes, the body was divided into 21 areas: 5 on the head, 2 on the dorsal body including the flippers, and 14 on the dorsal and ventral tail (Fig. 1). All images from each batch of sightings were reviewed, and each

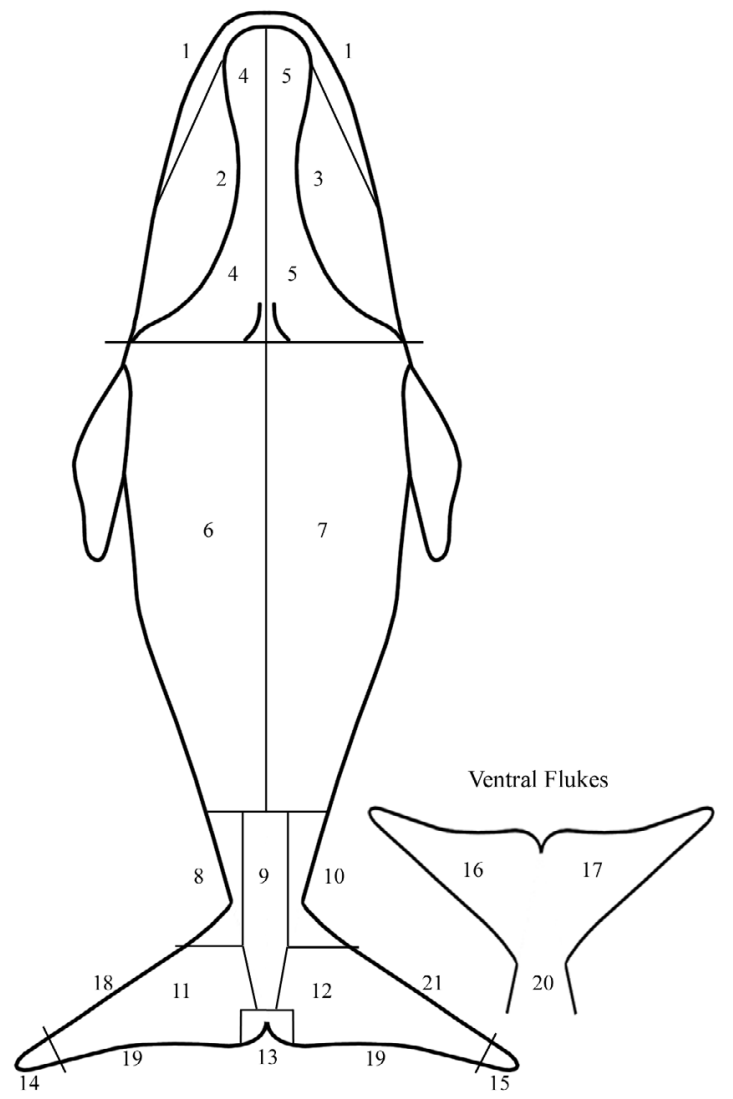

Fig. 1. Eubalaena glacialis. Body areas used for coding. The body areas most frequently bearing observable scars from rope are Areas 8, 9, and 10 body area seen in the images was coded if entanglement scarring or gear was detected.

For any entanglement scar detected, that body area was compared to previous batches of photographs of the animal to determine if the scar was new. After all batches had been coded, a report output listed each batch as a row of data with each body area with new entanglement scars notated. The time frames of occurrence of each new entanglement scar were compared to determine the minimum number of unique entanglement events and to narrow down as far as possible the time interval during which each event must have occurred. Take the example of 5 entanglement scars detected on 5 different body areas in 5 consecutive years (scar detected on Area 1 in 1980, on Area 2 in 1981, etc.). If none of the body areas had been previously photographed, then all 5 scars would be conservatively assigned to one unique entanglement event that occurred before 1980. However, if Area 2 had been seen definitely without any scars in 1980, then 2 entanglement events would be logged, one that occurred prior to 1980 and the other that occurred between 1980 and 1981. Data for each unique entanglement event included (1) date of detection (first date of the batch in which the unique event was first detected), (2) latest prior date when entanglement scarring was not present, (3) known age or age class of the whale on the date of entanglement detection, and (4) the whale's sex, if known. Age was categorized as 'juvenile' for an animal first sighted as a calf through $8 \mathrm{yr}$ old if it was not known to have given birth; 'adult' for a known age animal $\geq 9$ yr of age, or a female $<9$ yr of age sighted with a calf; and 'unknown' for any animal not first sighted as a calf with a sighting history $<8$ yr. Sex was determined either by visual assessment of the genital slit or a repeated association with a calf, or through genetic analysis of a skin biopsy. Scars related to entanglement were coded for all identified individuals in the Catalog from 1980 through 2009.

\section{Entanglement events and crude entanglement rate}

Total number of entanglement events

All unique entanglement events documented through 2009 were tallied for each individual and summarized for all individuals, and also for the subsets of individuals for which sex was known. The number of new entanglement detections as a proportion of the number of animals identified in each year 
starting with 1980 was calculated to assess annual variability in entanglement rates. However, the year a scar was detected may not represent the year the entanglement occurred (i.e. if the whale had not been seen for many years) so this analysis is only useful for demonstrating that entanglements have occurred (crude entanglement rate), but does not provide precise annual entanglement rates.

\section{Annual entanglement rate}

To determine the annual incidence of new entanglements, subsets of animals that showed definite evidence of a new entanglement by the second of 2 consecutive years in which they were sighted (i.e. 1980-1981, 1981-1982...) were counted from 1980 through 2009. The primary method of determining annual entanglement incidence was to review animals seen and adequately photographed in both years of each $2 \mathrm{yr}$ period. For an animal to be considered adequately photographed, clear images showing the entire area of the dorsal peduncle or one of the fluke insertion areas (Areas 8, 9, or 10; see Fig. 1) were required in both years to allow for inter-year comparisons. This area of the tail was chosen because previous analyses showed that the majority of entanglement scars were detected on the peduncle and fluke insertions (Hamilton et al. 1998). In addition to the animals adequately photographed in both years, there were other animals for which annual entanglement incidence could be determined. Calves and 1 yr old juveniles only had to be adequately photographed in the second year to be included (because their age alone indicates a limited time frame in which they could have acquired new scars). Similarly, any animal with an entanglement that was known to have occurred within the second year of the $2 \mathrm{yr}$ time frame was included. Lastly, because using only the peduncle for scarring leads to underestimation of entanglement rates, any animal with an entanglement scar detected on another part of the body in the second year of the 2 yr period that was clearly not present in the first year was also included.

For each sequential $2 \mathrm{yr}$ time period, the number of animals known to be entangled by the second year were tallied. That sum was divided by the total number of animals adequately photographed in both years, plus a count of the animals included by the 3 other criteria described above, to obtain a percentage of animals that were newly entangled by the second year in the given $2 \mathrm{yr}$ period. This treatment adjusts for variable annual photographic effort and whale sighting rates, and is the best analysis to determine temporal changes in entanglement rate. To analyze these scarring rates (including serious entanglement rate described below), the trend and directionality was assessed by log-transforming the yearly percentages and regressing against year.

Time frames of entanglements

Because right whales are not sighted on a daily basis, the location and actual date when each entanglement occurred usually cannot be determined. To estimate roughly when an entanglement occurred, a 'time frame' represents the period between the last sighting without the scarring and the first sighting with the scarring, i.e. the period within which the animal must have encountered the fishing gear. Entanglement time frames were classified as follows: (1) within $6 \mathrm{mo}$, (2) within $1 \mathrm{yr}$, (3) within $2 \mathrm{yr}$, (4) within $\geq 3 \mathrm{yr}$ and (5) unknown. All the time frames were summarized and graphed to show for each year: (1) the total number of entanglements that were first documented in that year, and (2) the breakdown (in percentages) of time frames during which those entanglements must have occurred.

\section{Age class at entanglement detection}

Previous studies have shown that calves and juveniles are more likely to become entangled than adults (Knowlton \& Kraus 2001). To investigate this further, we calculated the percentage of calves and juveniles seen each year with new entanglement scars or gear and compared those percentages to the same annual calculations for adults using a Wilcoxon signed-rank test. Although the age at detection does not necessarily indicate the exact age at entanglement, any detection that occurred before the animal became an adult would clearly represent an entanglement of a calf or juvenile. The count of such entanglements therefore can be considered a minimum estimate of the number of calf and juvenile entanglements.

\section{Serious entanglements}

Most right whales that become entangled apparently clear themselves of the gear and are left with only scars. Whales seen bearing fishing gear or with 
deep wounds from entanglement were categorized as having a serious entanglement (the term 'serious injury' from entanglement is used here interchangeably). The criteria used here to define serious entanglement included: (1) any animal seen bearing gear, or( 2) any animal with a cut deeper than $8 \mathrm{~cm}$ caused by an entanglement (Knowlton \& Kraus 2001) to account for the potential sub-lethal impacts related to gear either in the mouth, wrapped around a body part, or trailing behind the whale, or wounds that could lead to infection. In the Knowlton \& Kraus (2001) study, serious entanglements were subdivided into non-fatal, potentially fatal, and fatal. Any time a seriously entangled animal was subsequently sighted free of gear and with no obvious decline in condition, the entanglement was considered nonfatal. An entanglement was considered potentially fatal if the animal was wrapped in gear that would impede its movements or feeding behavior, or appeared to be in poor condition. Indicators of poor condition included slow swimming, pronounced skin lesions, graying of skin, not raising the flukes above the surface when diving, visible necrosis or swelling, and higher than normal levels of orange cyamids (whale lice) present on the skin of animals $>1 \mathrm{yr}$ old. In these cases, the animal typically disappeared without a carcass being found. Fatal entanglements were those that led to documented deaths where a carcass was found. The definition of 'serious injury' used by Knowlton \& Kraus (2001) and used in the present study is different from that used by NMFS, which considers serious injury to mean 'any injury that is likely to lead to mortality' (Angliss \& DeMaster 1998, Anderson et al. 2008).

The number of serious entanglements, independent of outcome, was tallied by year for 1980 through 2009 and divided by the number of individual whales photo-identified each year to determine the percentage that had been involved in a serious entanglement. These percentages were log-transformed and regressed against year. Finally, the demographic characteristics of seriously entangled animals were compared to the annual average percentage of calves and juveniles in the known age population over the time period.

\section{RESULTS}

\section{Total number of entanglement events}

Photographs of 626 individual animals sighted from 1980 through 2009, comprising 12894 batches, were reviewed for this study. A total of 1032 unique entanglement events were documented from either scars or fishing gear on the whale. Of the 626 animals reviewed, 519 (82.9\%) were entangled at least once, and 306 of the $519(59.0 \%)$ were entangled more than once. Whales showing evidence of multiple entanglements included 15 animals entangled 5 times, 5 entangled 6 times, and one that was entangled 7 times (mean $=1.99$ entanglements per animal) (Fig. 2). Of the 107 animals not coded as having entanglement scarring, 47 could not be adequately assessed because the tail region had never been photographed; therefore, the percentage documented with entanglement scars is likely a conservative figure.

Females and males had similarly high rates of entanglement (198 of 239 females, $82.8 \%$; 247 of 272 males, $90.8 \%$ ). The rate for individuals of unknown sex was considerably less ( 74 of $115,64.3 \%$ ). However, these latter animals were either seen rarely or were new to the Catalog, so there were fewer data from which to detect an entanglement event. Of the 445 whales of known sex that had been entangled at least once, the average number of entanglements was similar between females (2.19, SD 1.25, range 1 to 6$)$ and males (1.98, SD 1.06, range 1 to 7 ).

\section{Crude and annual entanglement rates}

Over the 30 yr study period, the overall crude entanglement rate, calculated as the average proportion of right whales with newly detected entanglement scars each year, was $15.5 \%$ (SD $5.5 \%$, range 8.6 to $33.6 \%$; Table 1). There was no significant trend in annual rate detected. The results from the log-transformed regression were the same as the non logtransformed data; therefore, the slopes presented are for the non log-transformed data $(\beta=0.13 \% \pm 0.12 \%$ $\mathrm{SE}, F_{1,28}=1.2, \mathrm{p}=0.286$ ).

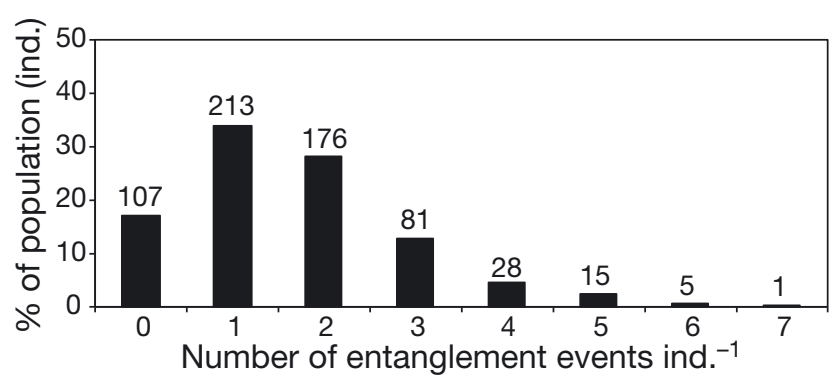

Fig. 2. Eubalaena glacialis. Frequency of occurrence of animals with evidence of different numbers of entanglement events, as a percentage of total animals in the population. Numbers above the bar represent numbers of individuals 
Table 1. Eubalaena glacialis. Annual tally of animals seen, new entanglement events recorded, and entanglement rates. For the calculation of annual entanglement, an animal was 'adequately seen' if the left, right, or dorsal peduncle was fully seen and well photographed in the given and prior calendar year. The annual entanglement rate was calculated from the number of new entanglements recorded by the second year of the $2 \mathrm{yr}$ period. The serious entanglement rate is the number of events divided by individuals seen. See 'Methods' for details of additional criteria used in the calculation of annual and severe entanglement rates

\begin{tabular}{|c|c|c|c|c|c|c|c|c|}
\hline \multirow[t]{2}{*}{ Year } & \multicolumn{3}{|c|}{ Crude entanglement } & \multicolumn{3}{|c|}{$\longrightarrow$ Annual entanglement } & \multicolumn{2}{|c|}{-Serious entanglement } \\
\hline & $\begin{array}{l}\text { Individuals } \\
\text { seen }\end{array}$ & $\begin{array}{c}\text { New } \\
\text { entanglements }\end{array}$ & $\begin{array}{l}\text { Rate } \\
(\%)\end{array}$ & $\begin{array}{l}\text { Ind. adequately } \\
\text { seen over } 2 \text { yr }\end{array}$ & $\begin{array}{c}\text { New } \\
\text { entanglements }\end{array}$ & $\begin{array}{l}\text { Rate } \\
(\%)\end{array}$ & $\begin{array}{l}\text { No. of } \\
\text { events }\end{array}$ & $\begin{array}{c}\text { Rate } \\
(\%)\end{array}$ \\
\hline 1980 & 65 & 9 & 13.8 & & & & 0 & 0.0 \\
\hline 1981 & 102 & 20 & 19.6 & 6 & 2 & 33.3 & 1 & 1.0 \\
\hline 1982 & 100 & 18 & 18.0 & 13 & 2 & 15.4 & 0 & 0.0 \\
\hline 1983 & 76 & 11 & 14.5 & 14 & 7 & 50.0 & 1 & 1.3 \\
\hline 1984 & 115 & 14 & 12.2 & 19 & 5 & 26.3 & 1 & 0.9 \\
\hline 1985 & 104 & 15 & 14.4 & 21 & 5 & 23.8 & 1 & 1.0 \\
\hline 1986 & 152 & 19 & 12.5 & 29 & 6 & 20.7 & 2 & 1.3 \\
\hline 1987 & 152 & 13 & 8.6 & 25 & 4 & 16.0 & 1 & 0.7 \\
\hline 1988 & 198 & 24 & 12.1 & 31 & 6 & 19.4 & 0 & 0.0 \\
\hline 1989 & 205 & 18 & 8.8 & 39 & 6 & 15.4 & 0 & 0.0 \\
\hline 1990 & 145 & 29 & 20.0 & 46 & 21 & 45.7 & 2 & 1.4 \\
\hline 1991 & 161 & 15 & 9.3 & 23 & 7 & 30.4 & 0 & 0.0 \\
\hline 1992 & 131 & 19 & 14.5 & 27 & 9 & 33.3 & 0 & 0.0 \\
\hline 1993 & 175 & 20 & 11.4 & 29 & 9 & 31.0 & 2 & 1.1 \\
\hline 1994 & 207 & 38 & 18.4 & 60 & 16 & 26.7 & 5 & 2.4 \\
\hline 1995 & 220 & 22 & 10.0 & 82 & 11 & 13.4 & 2 & 0.9 \\
\hline 1996 & 219 & 42 & 19.2 & 86 & 27 & 31.4 & 2 & 0.9 \\
\hline 1997 & 247 & 83 & 33.6 & 124 & 46 & 37.1 & 6 & 2.4 \\
\hline 1998 & 219 & 23 & 10.5 & 115 & 20 & 17.4 & 2 & 0.9 \\
\hline 1999 & 228 & 57 & 25.0 & 106 & 21 & 19.8 & 4 & 1.8 \\
\hline 2000 & 234 & 34 & 14.5 & 148 & 20 & 13.5 & 7 & 3.0 \\
\hline 2001 & 278 & 41 & 14.7 & 137 & 24 & 17.5 & 5 & 1.8 \\
\hline $2002^{\mathrm{a}}$ & 300 & 45 & 15.0 & 133 & 25 & 18.2 & 8 & 2.7 \\
\hline 2003 & 309 & 30 & 9.7 & 93 & 15 & 16.1 & 4 & 1.3 \\
\hline 2004 & 281 & 43 & 15.3 & 78 & 29 & 37.2 & 4 & 1.4 \\
\hline 2005 & 347 & 62 & 17.9 & 133 & 34 & 25.6 & 3 & 0.9 \\
\hline 2006 & 339 & 54 & 15.9 & 173 & 44 & 25.4 & 2 & 0.6 \\
\hline 2007 & 376 & 94 & 25.0 & 183 & 79 & 43.2 & 4 & 1.1 \\
\hline 2008 & 386 & 71 & 18.4 & 211 & 59 & 28.0 & 9 & 2.3 \\
\hline 2009 & 413 & 49 & 11.9 & 219 & 42 & 19.2 & 8 & 1.9 \\
\hline \multicolumn{3}{|c|}{ Mean (SD) } & $15.5(5.5)$ & & & $.9(10.0)$ & & $1.2(0.8)$ \\
\hline
\end{tabular}

From the restricted dataset that considered only whales known to be newly entangled by the second year of each $2 \mathrm{yr}$ time period, the annual entanglement rate ranged from 13.4 to $50.0 \%$ with an annual average of $25.9 \%$ (SD 10.0\%; Table 1). The number of adequately photographed animals increased over the time period, but no significant trend in entanglement rate was detected $(\beta=-0.093 \% \pm 0.23 \% \mathrm{SE}$, $\left.F_{1,27}=0.17, \mathrm{p}=0.685\right)$.

\section{Time frame of entanglement detection}

During the 1980s, only one-third of all entanglement detections were detected within a $2 \mathrm{yr}$ time frame. This steadily improved over time and during the 2000 s, $72 \%$ of the entanglements were detected within a 2 yr time frame, with $61 \%$ detected within a 1 yr time frame (Fig. 3).

\section{Relative age at entanglement detection}

For all but 4 years (1981, 1982, 1984 and 1986), the percentage of calves and juveniles entangled exceeded the percentage of adults entangled (Fig. 4). This difference was significant (Wilcoxon signed-rank test, $Z=$ $3.82, p=0.0001$ ). The average percentage of calves and juveniles entangled across all years was $23.0 \%$ (SD $9.6 \%$ ) compared to $12.1 \%$ (SD $7.8 \%$ ) for adults. 


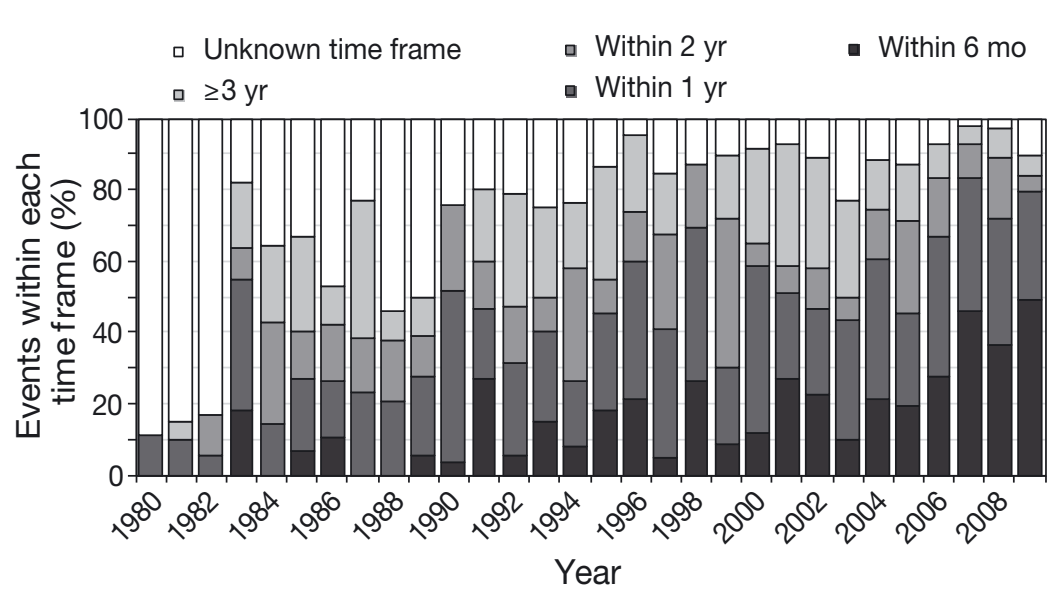

Fig. 3. Eubalaena glacialis. Detection of entanglement events within each time frame

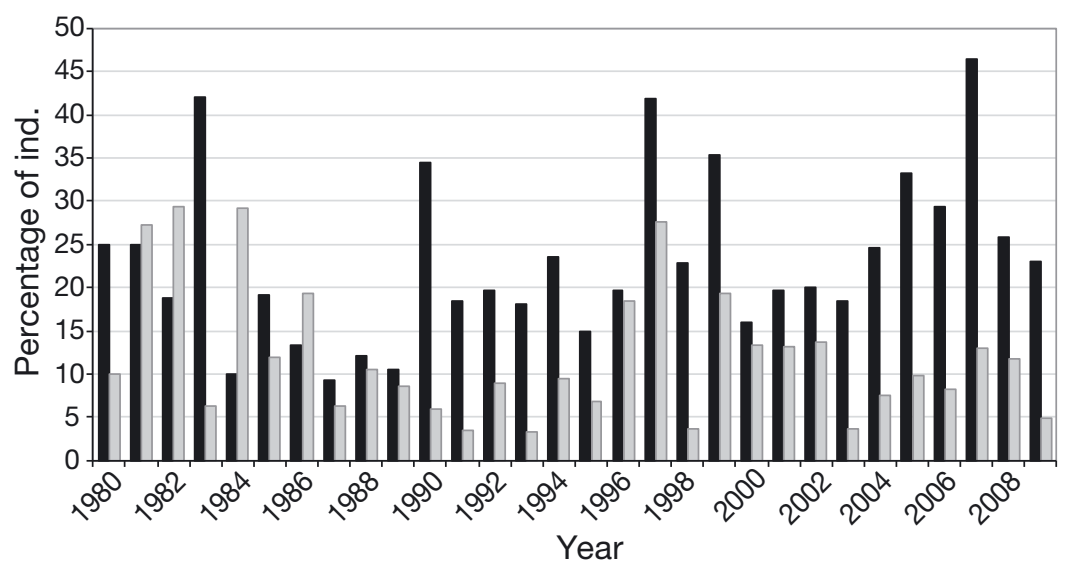

Fig. 4. Eubalaena glacialis. Percentage of calves/juveniles (black bars) and adults (gray bars) seen in given year with evidence of new entanglement

\section{Serious entanglements}

Between 1980 and 2009, there were 86 serious entanglement events. The percentage of seriously entangled animals versus the number of animals photo-identified each year ranged from 0 to $3.0 \%$, with an average of $1.2 \%$ (SD $0.8 \%$; Table 1$)$. These data showed a significantly increasing trend $(\beta=$ $\left.0.048 \pm 0.016 \% \mathrm{SE}, F_{1,28}=9.3, \mathrm{p}=0.0049\right)$. The only years in which no animals were observed to be seriously entangled occurred prior to 1993. The highest number observed was 9 in 2008.

Of the 74 seriously entangled animals of known age class from 1980 to 2009 (excluding 12 animals of unknown age when seen entangled), $51.4 \%$ of them were calves or juveniles. During this same time period, the average annual percentage of juveniles in the known age population was only $28.7 \%$ (SD 9.5\%).

\section{DISCUSSION}

Bycatch in non-mobile fishing gear leading to incidental mortality or serious injury has been identified as a worldwide conservation concern for many species of marine mammals including large whales (Read et al. 2006). Through 2009, 82.9\% of North Atlantic right whales have experienced at least one entanglement with some animals having experienced 6 or 7 encounters with gear. Calves and juveniles were entangled proportionally more than adults in all but 4 years of this 30 yr study. Further, young whales do not appear to learn to avoid fishing gear after becoming entangled, as $51.3 \%(157 / 306)$ of the individuals that were entangled multiple times had been first entangled as a calf or juvenile. Finally, the higher incidence of serious entanglements in calves and juveniles suggests that they are more likely than adults to be trapped in fishing gear or to suffer deep wounds from the interaction.

Longitudinal studies of North Atlantic right whales provide a unique opportunity to monitor the annual rates and the severity of entanglements, both of which can be used to assess whether management strategies are reducing right whale bycatch in fishing gear. On an annual basis, entanglement rates in this population averaged $15.5 \%$ of all animals sighted, and averaged $25.9 \%$ of a subset of animals considered adequately photographed from one year to the next. In no year has the entanglement rate ever approached zero, indicating that contact with rope is an ever-present, predictable threat to this population. Our study revealed a significantly increasing trend in the occurrence of serious entanglement events, as a percentage of animals photo-identified. This is supported by the fact that the only years in which no serious entanglements were detected occurred prior to 1993. Serious entanglements are more readily apparent from photographs than minor scarring is. If there were a detection bias, it would be more likely to show up in the crude entanglement rate, not in the serious entanglement rate. The finding that crude and annual entanglement rates show no increasing trend, but serious entanglements do, suggests that it is not just the number of entanglements that are of concern. Apparently changes in gear type or fishing methods, or 
changes in right whale distribution, have altered the impact of entanglements without changing the rates; however, the underlying reasons for this can only be speculated on. Changes in rope manufacturing resulting in more durable and stronger rope may have allowed for heavier gear to be used and/or an expansion of areas fished. The possible effects of rope manufacturing changes are being explored by the lead author of this paper. Another variable is the groundfish collapse in the USA that occurred in the early 1990s, which resulted in a shift from gillnetting to lobster fishing. This transition may have resulted in a different type of fishery practice or whale interaction with the gear. Other variables such as shifts in right whale distribution may also impact our finding. Whatever the reasons for this apparent increase in entanglement severity, one worrying feature is that slightly over $50 \%$ of the seriously entangled right whales were juveniles, even though they only constitute $28.7 \%$ of the population.

All of these methods can be used to assess the efficacy of entanglement reduction measures. The evaluation of all whales sighted in a given year with new scars or carrying gear provides information that entanglements are occurring in the population. However, these numbers cannot appropriately be used to monitor annual rates since they include all new entanglement detections independent of when a given interaction might have occurred. The approach using animals known to have been newly entangled by the second year of a given 2 yr period provides a useful metric of annual rates of contact with rope. Finally, analyses of serious entanglements will help determine if gear modifications aimed at reducing entanglement severity are influencing the nature of entanglement interactions and their overall impact on the whales.

The time frames of entanglement detections have narrowed since the 1980s, suggesting that efforts to monitor this population have improved over time. This improvement is likely due to changes in data collection protocols (full body image suites which began in the late 1980s), the advent of digital photography which allows for zooming in to confirm if a scar wraps, and increased shipboard survey effort. Despite this detection improvement, there was no trend upwards in crude or annual entanglement rates which would be expected if this improvement in detection had introduced a bias. Yet, even with detection improvement, the geographic locations where entanglements occur and the type of gear involved are rarely known (Johnson et al. 2005). This lack of information makes management extremely challenging.
A high proportion of known individuals in this population are photo-identified annually, but numerous factors influence the collection and analysis of entanglement scarring data, and rates are probably underestimated. First, shipboard and aerial platforms are not equivalent in this assessment, since entanglement scars are difficult to assess from aerial photos. Second, short-term shifts in the distribution of right whales have occurred during the $30 \mathrm{yr}$ study period (Kenney 2001), interrupting the regular collection of scarring data because whales were outside the typical survey areas. Finally, vessel-based photographic surveys (from which most entanglement data are obtained) have been variable and infrequent or absent in some of the known right whale habitats. To maintain annual monitoring capabilities for managers, vessel-based survey effort should be implemented or expanded in more high-use right whale areas to maximize the detections of entanglements within short time frames. The right whale scientific community and NMFS are presently considering an expanded use of passive acoustic monitoring to assess the presence and absence of right whales in certain habitats. One must bear in mind, however, that any concurrent reduction in visual effort will reduce our ability to assess the level of entanglements occurring in this population.

Right whales are protected under the US Endangered Species Act of 1973, the US Marine Mammal Protection Act of 1972, and the Canadian Species at Risk Act of 2002. For this species, the goal of these 3 statutes is to ensure population recovery by reducing threats from human activities. In the USA, NMFS has implemented several regulations since 1997 intended to reduce the frequency and seriousness of whale entanglements. These currently include the use of weak links to connect the vertical line to the buoy system for pot and gillnet gear; weak links between and within gillnet panels; seasonal gillnet closures off the Florida and Georgia coast, Cape Cod Bay, and the Great South Channel; and the use of sinking groundline (versus floating groundline) between pots and for gillnet anchoring lines for most east coast US waters except for certain exempted areas nearshore (see www.nero.noaa.gov/whaletrp/ plan/ALWTRPGuide.pdf for details of these requirements). These requirements have been implemented incrementally, with the sinking groundline rule most recently put in place in April 2009. Despite these efforts, 4 serious entanglements were documented in 2010, and 11 in 2011. The last unregulated segment of fixed gear in US water is the vertical buoy lines, which remain a serious entanglement threat to all 
large whales (Johnson et al. 2005). Finally, most of the right whale population spends several months of each year in Canadian waters, where no regulatory measures are in place to mitigate fishery interactions.

The scarring data presented here demonstrate that right whale entanglement rates based on both scarring and presence of fishing gear on the whales are up to 10 times higher than those recorded by counting only whales observed carrying gear. Documented entanglements with gear represent only those events in which either the animal survived the initial encounter and was later sighted with gear on it, or the carcass was found, reported, and accessible for examination. Considering the high rates of entanglement from the scarring data and the fact that large whales including right whales are known to have been anchored or drowned in gear, it is likely that some whales die during or shortly after an entanglement with no photo-documentation and are never seen again. In addition to the documented deaths and disappearances of animals observed bearing fishing gear, the sub-lethal effects of severe wounding or repeated entanglements may include reduced reproduction and increased susceptibility to disease (Knowlton \& Kraus 2001, Kot et al. 2009). The dedicated efforts to disentangle right whales that are sighted with what is judged to be life-threatening entanglements have clearly saved the lives of some whales, yet such efforts are not a long-term solution to the entanglement problem.

The North Atlantic right whale population is not the only population of large whales that has experienced a high rate of entanglement. A study of humpback whales in the North Atlantic found $64.9 \%$ of the population to have entanglement scarring when first assessed in 2003 and acquiring new scarring at an average annual rate of $12.1 \%$ (Robbins 2009). A study of humpback whales off southeast Alaska found $71 \%$ of that population to have entanglement scarring, with an annual acquisition rate of $8 \%$ between 2002 and 2003 (Neilson et al. 2009). Other species of large whales also experience entanglement (Read et al. 2006; see NOAA Stock Assessment Reports at www.nmfs.noaa.gov/pr/sars/), but there are relatively few studies with sufficiently detailed photo-identification data to assess population-wide and annual rates of entanglement.

Entanglement of large whales in fishing gear has emerged as one of the urgent conservation issues of our time. Fishing gear mortalities for several species classified as endangered probably exceed all other causes of mortality combined. As managers attempt to regulate fisheries to reduce such interactions and meet the legal requirements aimed at mitigating harm to endangered large whales, it is essential to develop methods to monitor their effectiveness. Here we have shown that appropriate documentation of scarring and of animals bearing gear can provide critical information about the efficacy of efforts to mitigate entanglements of right whales. In addition it is essential to supplement this information with gear marking to identify the gear types and fishing locations posing the most risk, to continue development and implementation of effective gear modifications, and to utilize seasonal area closures in high-risk areas. For right whales, the evidence presented here indicates that the efforts made since 1997 to reduce entanglements and fatalities from fishing gear entanglement have not yet succeeded. Further actions are needed immediately in both the USA and Canada to effectively eliminate entanglements in order to help this species recover.

Acknowledgements. This work was supported over the long term by the NMFS, Northeast Fisheries Science Center. The North Atlantic Right Whale Consortium approved access to the Catalog to carry out this study. We thank all those who have contributed photographic sightings data to the Catalog. The collaborative nature of the Consortium members for data access has ensured the most robust analyses possible. We also express tremendous gratitude to members of the Atlantic Large Whale Disentanglement network who carry out the risky work of disentangling large whales. We thank the many people both within New England Aquarium's right whale team and those contributors who carry out the dedicated work of matching sightings to the Catalog. Finally, we thank Lindsay Cooper and Laura Lane Cooke, formerly of NEAq, who helped greatly with the scar coding efforts.

\section{LITERATURE CITED}

Anderson MS, Forney KA, Cole TV, Eagle T and others (2008) Differentiating serious and non-serious injury of marine mammals: report of the serious injury technical workshop, 10-13 Sep 2007, Seattle, Washington, DC. NOAA Tech Memo NMFS-OPR-39

Angliss RP, DeMaster DP (1998). Differentiating serious and non-serious injury of marine mammals taken incidental to commercial fishing operations: report of the serious injury workshop, 1-2 Apr 1997, Silver Spring, MD. NOAA Tech Memo NMFS-OPR-13

Cassoff RM, Moore KM, McLellan WA, Barco SG, Rotstein DS, Moore MJ (2011) Lethal entanglement in baleen whales. Dis Aquat Org 96:175-185

Hamilton PK, Knowlton AR, Marx MK (2007) Right whales tell their own stories: the photo-identification catalog. In: Kraus SD, Rolland RM (eds) The urban whale: North Atlantic right whales at the crossroads. Harvard University Press, Cambridge, MA, p 436-459

Hamilton PK, Marx MK, Kraus SD (1998) Scarification analysis of North Atlantic right whales (Eubalaena gla- 
cialis) as a method of assessing human impacts. Report to National Marine Fisheries Service, Northeast Fisheries Science Center, Woods Hole, MA. NOAA Contract \#46 EANF-6-0004. www.nefsc.noaa.gov/publications/reports/ EANF-6-004.pdf

Hunt KE, Rolland RM, Kraus SD, Wasser SK (2006) Analysis of fecal glucocorticoids in the North Atlantic right whale (Eubalaena glacialis). Gen Comp Endocrinol 148: 260-272

Johnson AJ, Salvador G, Kenney JF, Robbins J, Kraus SD, Landry S (2005) Fishing gear involved in entanglements of right and humpback whales. Mar Mamm Sci 21: 635-645

Kenney RD (2001) Anomalous 1992 spring and summer right whale (Eubalaena glacialis) distributions in the Gulf of Maine. J Cetacean Res Manag 2(Spec Issue):209-223

Knowlton AR (2005) A review of gear modifications and fishing practices aimed at reducing the level and frequency of entanglements with right and humpback whales in the western North Atlantic. Report to National Marine Fisheries Service, Northeast Region, Gloucester Point, MA. NOAA Contract \#40EMNF300159

Knowlton AR, Kraus SD (2001) Mortality and serious injury of northern right whales (Eubalaena glacialis) in the western North Atlantic Ocean. J Cetacean Res Manag 2(Spec Issue):193-208

Knowlton AR, Cooper LA, Hamilton PK, Marx MK, Pettis HM, Kraus SD (2008) Analysis of scarring on North Atlantic right whales (Eubalaena glacialis): monitoring rates of entanglement interaction 1980-2004. Report to National Marine Fisheries Service, Northeast Fisheries Science Center, Woods Hole, MA. NOAA Contract \#EA133:F-03-SE-0323

Editorial responsibility: Hans Heinrich Janssen, Oldendorf/Luhe, Germany
Kot BW, Ramp C, Sears R (2009) Decreased feeding ability of a minke whale (Balaenoptera acuturostrata) with entanglement-like injuries. Mar Mamm Sci 25:706-713

Kraus SD (1990) Rates and potential causes of mortality in North Atlantic right whales (Eubalaena glacialis). Mar Mamm Sci 6:278-291

Kraus SD, Moore KE, Price CA, Crone MJ, Watkins WA, Winn HE (1986) The use of photographs to identify individual North Atlantic right whales (Eubalaena glacialis). Rep Int Whaling Comm 10(Spec Issue):145-151

Kraus SD, Brown MW, Caswell H, Clark CW and others (2005) North Atlantic right whales in crisis. Science 309: 561-562

Moore MJ, Knowlton AR, Kraus SD, McLellan WA, Bonde RK (2004) Morphometry, gross morphology and available histopathology in North Atlantic right whale (Eubalaena glacialis) mortalities (1970-2002). J Cetacean Res Manag 6:199-214

Neilson JL, Straley JM, Gabriele CM, Hills S (2009) Nonlethal entanglement of humpback whales (Megaptera novaeangliae) in fishing gear in northern Southeast Alaska. J Biogeogr 36:452-464

Read AJ, Drinker P, Northridge S (2006) Bycatch of marine mammals in U.S. and global fisheries. Conserv Biol 20: 163-169

Robbins J (2009) Scar-based inference into Gulf of Maine humpback whale entanglement: 2003-2006. Report to National Marine Fisheries Service, Northeast Fisheries Science Center, Woods Hole, MA. NOAA Contract \#EA133F04SE0998

Weinrich M (1999) Behavior of a humpback whale (Megaptera novaeangliae) upon entanglement in a gillnet. Mar Mamm Sci 15:559-563

Submitted: April 4, 2012; Accepted: July 4, 2012

Proofs received from author(s): September 25, 2012 